\title{
Note on some Supposed Hybrids between the Turbot and the Brill.
}

\author{
By
}

\section{Ernest W. L. Holt.}

THE specimens conform to a type which appears to be fairly well known to Grimsby fishermen, and fish merchants, and which is always regarded by them as the offspring of the parents mentioned in the title. The object of the present note is to discuss the probabilities of the correctness of this diagnosis as fully as the material allows. The form can hardly be said to be rare, since within two years I have secured three specimens, while I have heard of several others having been present in the market. In some old manuscript notes kindly lent me by my friend Mr. G. L. Alward I find descriptions which apply to two fish of the same type, while Dr. Günther tells me that he has received several from London fish merchants.

Notes of apparently similar fish have from time to time appeared in both scientific and sporting publications, since Day (Fish G. Brit., ii, p. 13) refers to specimens described in the Proceedings of the Zoological Society and the Field, while Smitt has recently given both description and figure (Hist. Skand. Fish., ed. 2, p. 446).

\section{Description of Specimens.}

The specimens which have come under my own observation are three in number; they were trawled in the North Sea, one in June,1892, and the others in the same month of the following year.

Colour.-In the fresh condition they presented so close a resemblance in colour to brill that they might easily have been mistaken for a fish of that species. The brill, as is well known, is of a reddish-brown colour on the ocular side, diversified with sundry lighter markings, which markings are retained to some extent after death. The turbot, on the other hand, as it appears in the market, is of nearly uniform olive-brown colour, the lighter markings conspicuous in living examples being rapidly masked by post-mortem expansion of the darker chromatophores. Specimens of the two species may certainly 
be found to approach each other in general coloration, but it will be conceded that the broad distinction which I have laid down holds good in the majority of cases. Preservation in alcohol rather emphasises the distinction in the case of brill and turbot, but, of the three hybrids, one acquired after preservation a colour corresponding to that of a turbot similarly preserved, while the other two retained the reddish tinge of the brill.

Scales.-The character of the scales forms the most striking feature in the three specimens, and is practically identical in all. In place of the imbricating scales of the brill or the isolated tubercles of the turbot, both sides of the body are beset with large more or less oval, cycloidal scales, which, though never actually imbricating, are placed fairly close together. On the ocular side of the body each scale is very thin and slightly convex, the most prominent part being at the central point of the concentric system of faintly marked ridges situate behind the middle line of the scale. The larger scales exhibit a number of faint grooves for insertion anteriorly, but there is no free edge. The whole scale is between two pigmented layers of dermis, but the upper layer on the ocular side is in most cases incomplete at the greatest convexity of the scale, so that the latter is, to that limited extent, exposed. The skin is so thin that it might readily be abraded, and to what extent the partial exposure of the scales may be due to artificial causes (e. g. injury in the trawl, \&c.) it is impossible to say. The largest scales occur on the lateral parts, especially on the caudal peduncle, and anteriorly in the neighbourhood of the lateral line. In a specimen of $43.3 \mathrm{~cm}$, , one of the largest from this region measures 5 by $3.5 \mathrm{~mm}$. Towards the abdominal region the scales become smaller and irregularly rounded, as also on parts of the interspinous ridges. On the jaws they are small and circular, rather small and nearly round on the head, except on the malar part, where they become larger and elongate. On the fin-rays the scales are very small, and here alone they show some attempt at imbrication. On the blind side the scales are essentially similar to those of the ocular side, but are less convex and almost invariably veiled by skin. They correspond in distribution, with the exception that there are only a few on the mandible and none on the maxilla or the prominent parts of the gill-cover, while the fin-rays are only feebly scaled.

Dimensions. - Of the three specimens two were measured after preservation, the third being measured both in the fresh and preserved conditions. 


\begin{tabular}{|c|c|c|c|c|}
\hline 1 & $\begin{array}{l}\text { Total length. } \\
17 \frac{3}{\frac{3}{8}} \text { in. }\end{array}$ & $\begin{array}{l}\text { Total without cauda } \\
14 \text { in. }\end{array}$ & $\begin{array}{l}\text { Length of head. } \\
4^{\frac{5}{5}} \text { in. }\end{array}$ & $\begin{array}{l}\text { Greatest height. } \\
9 \frac{19}{\frac{9}{2}} \text { in. }\end{array}$ \\
\hline & $18 \frac{1}{8}$ in. & - 15 in. & $4 \frac{7}{8}$ in. & $9 \frac{1}{n}$ in. \\
\hline & $18 \frac{3}{4}$ in. & $15 \frac{13}{16}$ in. & 5 iu. & $10 \frac{3}{8}$ in. \\
\hline & 19 in. & 16 in. & $5 \mathrm{in.}$ & $10 \frac{1}{2}$ in. \\
\hline
\end{tabular}

Fin-ray Formula :
A.
D. 69
A. 52.
B.
D. 72
A. 54 .
C.
D. 76
A. 54 .

Comparative.-The foregoing description will probably suffice, minor details of character being more conveniently treated only in comparison to those of the species to the union of which the forms before us have been imputed. It may at once be said that all three examples are females, but not one of them is sexually mature. It is significant that all three were caught in the month of June, a period at which the ovary would certainly be enlarged (or evidently recently shotten) in either brill or turbot, and fish of either species as large as those before us (viz. $17 \frac{1}{8}$ to 19 inches) would as a rule be sexually mature. In fact, an immature female brill of even the smallest size quoted is decidedly rare. Apart from the scales, turbot and brill are most readily distinguished by the proportion borne by the height to the length of the body, the turbot being the deeper fish of the two. The proportions laid down in ichthyological works, however, are of no great service, since the size of the individuals on which such proportions are based is never forthcoming, and it is well known that the proportions of a fish are subject to constant change with the growth. Therefore, in comparing our supposed hybrids with the brill and turbot, it appeared best to give the proportions of a series of forms of either species agreeing as nearly as possible with them in size, as in the appended table. The total length, without the caudal, given in the first column is taken as the unit, and the other dimensions are expressed in decimals of this unit.

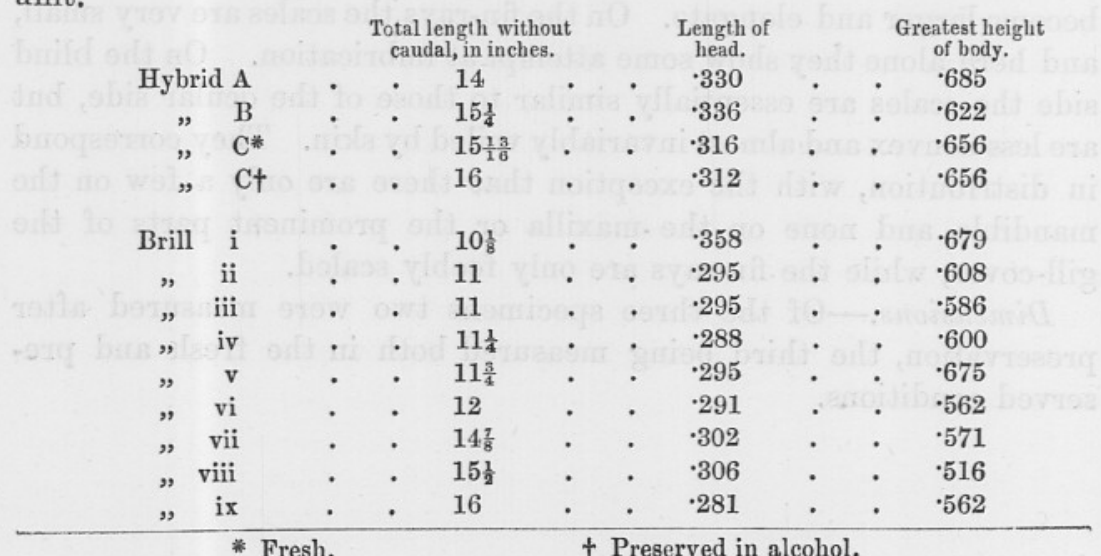




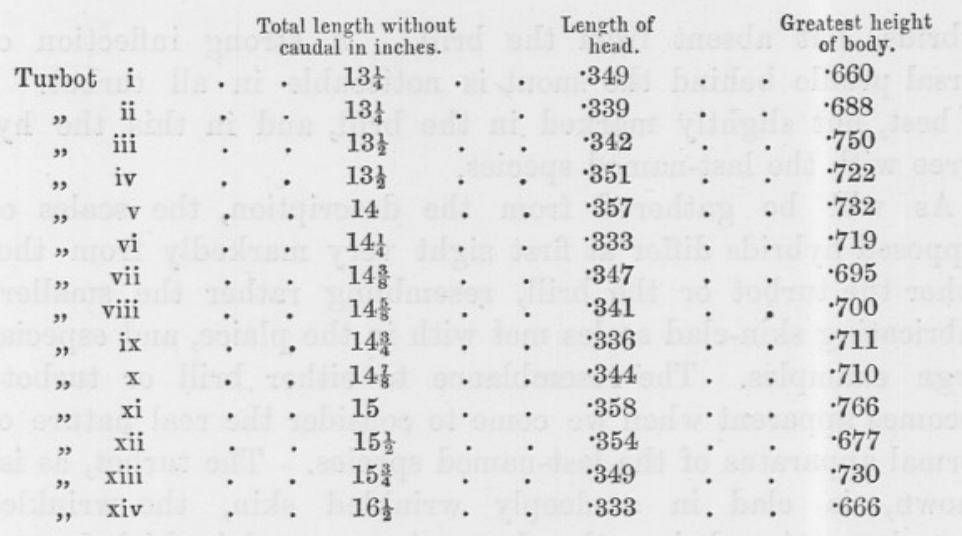

The details of proportion of brill and turbot given in the above table show how easily a diagnosis based on these features alone may be vitiated by individual variation ; but, on the whole, the condition exhibited by the hybrids appears to be an intermediate one, not inclining very strongly to either species. It must be remarked that the measurements from which the proportions of the brill and turbot are deduced were taken in the fresh condition, but comparison of the two series of proportions of hybrid $\mathrm{C}$ shows that the figures are not greatly affected by preservation in alcohol. The variation which is exhibited by the hybrids amongst themselves is evidently not greater than is met with in perfectly normal examples of either species.

The fin-ray formula given above is certainly intermediate in character, but inclines, among material collected from the same locality, rather to the brill than the turbot. Thus nine turbot give D. $60-67$, A. $42-48$; the three hybrids D. $69-76$, A. $52-54$; and four brill D. $77-81$, A. 57-62. The first dorsal ray is in each case shorter than the second, as in turbot, but its extremity is divided, as in the brill.

The number of vertebræ is an important distinction between the turbot and the brill. The only hybrid in which I have counted these structures agrees in this respect with the last-named species.

In certain minor characters of doubtful importance the hybrids appear to be intermediate. The vomerine teeth are rather more numerous in the brill than in the hybrids, and much more numerous than in those turbot which I have examined. In the teeth of the upper jaw the hybrids agree best with the brill, the teeth being more slender than those of the turbot. The peculiar papillation of the lips is probably a very variable character. Such turbot as I have examined have an outer row of semicircular pigmented labial tags or papillæ; this feature was slightly represented in the 
hybrids, but absent from the brill. A strong inflection of the dorsal profile behind the snout is noticeable in all turbot. It is, at best, but slightly marked in the brill, and in this the hybrids agree with the last-named species.

As will be gathered from the description, the scales of the supposed hybrids differ at first sight very markedly from those of either the turbot or the brill, resembling rather the smaller nonimbricating skin-clad scales met with in the plaice, and especially in large examples. The resemblance to either brill or turbot only becomes apparent when we come to consider the real nature of the dermal apparatus of the last-named species. The turbot, as is well known, is clad in a deeply wrinkled skin, the wrinkles, on close inspection, being the depressions or sulci which separate a very irregularly arranged series of rather vesicular papillæ. Scales are only represented by a series of tubes, with very imperfect dorsal and ventral flanges, in connection with the sense-organs of the lateral line, and by large isolated tubercles, the apices or bosses of which are naked, while the bases are deeply embedded in the derma by a series of twisted irregular radical processes. Such tubercles in British examples are present only on the ocular side, except in "cyclopean" or in partially ambicolorate fish, in which they occur also to a greater or less extent on the blind side. In Norwegian fish, however, the tubercles, which are as a rule more numerous on the ocular side than in examples from our own seas, occur not infrequently on the blind side without any accompanying pigmentation. The skin papillæ and wrinkles are equally present on either side in all examples.

On the general surface of the body there is no very striking resemblance between the papillæ of the turbot and the scale capsules of the hybrid, but at the base of the interspinous ridges the skin of the two forms presents a fairly close resemblance, and I was led by this to institute a comparison of the skin armour of the two forms, which led me ultimately to the conclusion that the papillæ of the turbot's skin were undoubtedly scale-capsules, in which the scales had failed to develop. This view I believed to be novel, but on the appearance of Professor Smitt's edition of Fries, Ekstrom, and Van Wright's History of Skandinavian Fishes I found it set forth (p. 434) that the skin is furnished with " soft verrucose closed scale-sacs." This interpretation of the papillæ may either be original, or, since the work in question is largely a compilation, may be collated from the observations of some earlier Skandinavian ichthyologist. I am entirely in accord with it, but, if it is set forth for the first time in the work referred to, it runs the risk of rejection for want of evidence, since the matter is nowhere alluded to in 
the context. I propose, therefore, to discuss the question very briefly in this note.

In the appended woodcut, Fig. 2, $a$ is a group of scales and capsules from the lateral line of a hybrid (blind side), and the resem-
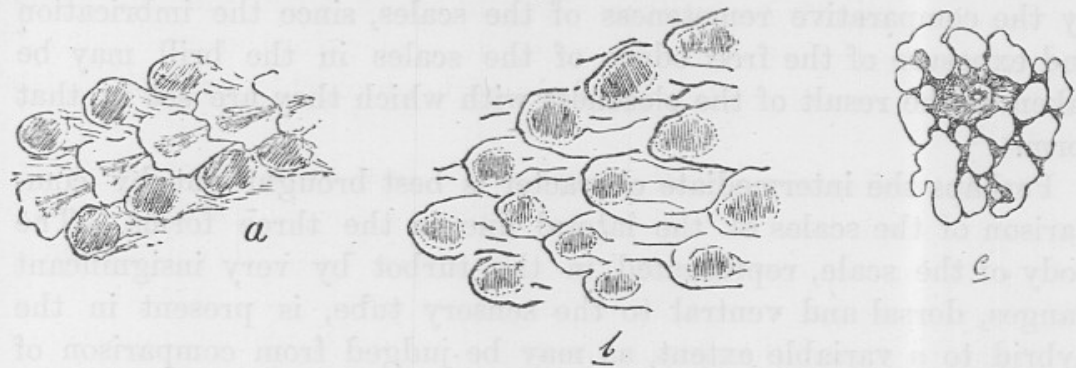

c

FIG. 2.- $a$. Group of seales from region of lateral line of hybrid (blind side). $\quad b$. Group of scales from base of interhæmal ridge of hybrid (blind side). c. Tubercle and surrounding papillæ of turbot (ocular side); pigment omitted from papillæ.

blance to true scale capsules of the lateral line of the normal turbot is sufficiently noticeable. The surrounding scale capsules, however, are far more regular than the papillæ of the turbot, besides enclosing a very conspicuous ovoidal scale. In a group of scales $(b)$ from the base of the interhæmal ridge of a hybrid (blind side) we find that the sulci, in this case obviously in connection with true scale capsules, present an appearance closely similar to those met with between the papillæ of the same region in the turbot. $c$ shows a single tubercle of a nearly adult turbot (ocular side) surrounded by a group of papillæ, the apex of the tubercle projecting through the skin in precisely the same manner as I have described in the case of some of the scales of the ocular side in the hybrids. The smallest turbot (47 inches) in which I have found the tubercles visible to the naked eye has these structures in the form of blunt cones, the bases of which are elongated anteriorly, but entirely destitute of radical processes. Radial insertion sulci are also absent, but such is also the case in some scales of the hybrid. In fact, save that it is much thicker in proportion, the young tubercle of the turbot is not distinguishable in structure from the scale of the hybrid. The tubercles of the turbot, as is well known, have no regularity either of disposition or of number, and I think that there can be little doubt but that the intervening papillæ are merely barren scale-sacs, which become to some extent broken up and anastomosed with the growth of the fish. If this is the case the intermediate nature of the scales of the hybrid becomes apparent.

More sparingly distributed than those of the brill, though more numerous than in even the most thickly tubercled Norwegian 
turbot, the scales retain characters which closely resemble a very early condition in the development of a turbot's tubercle, as well as the perfect condition of the scale of a brill. The persistence of the skinny covering has probably no greater significance than is explained by the comparative remoteness of the scales, since the imbrication and exposure of the free edges of the scales in the brill may be taken as the result of the closeness with which they are set in that form.

Perhaps the intermediate character is best brought out by comparison of the scales of the lateral line in the three forms. The body of the scale, represented in the turbot by very insignificant flanges, dorsal and ventral to the sensory tube, is present in the hybrid to a variable extent, as may be judged from comparison of $b$ and $c$ (Fig. 3). In no case is it so well developed as in the brill $(a)$, nor so insignificant as in the turbot $(d)$.
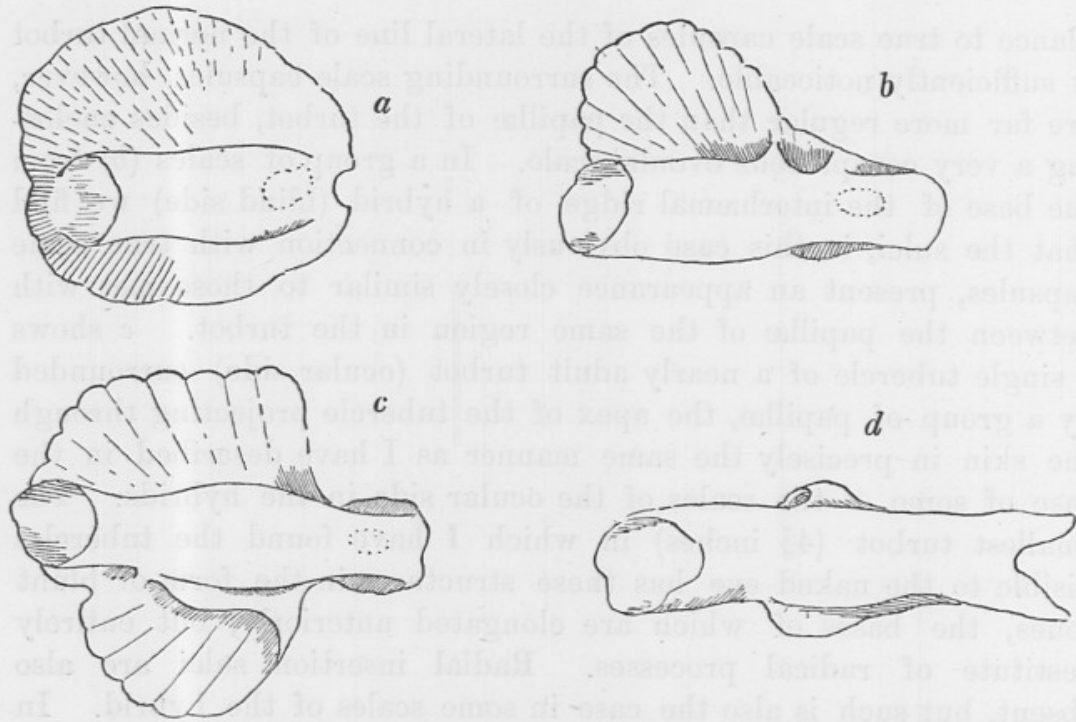

Fic. 3.- $a$. Scale from lateral line of brill (blind side). $b, c$. From hybrid (blind side) d. From turbot (blind side).

Conclusions.-In discussing the parentage of these forms it appears to me that there are only two alternative theories, since it is not likely to be seriously contended that they belong to a distinct species. They may be either hybrids, or "sports" of either the turbot or the brill. If the latter is the true explanation it is at least remarkable that the variation should in so many points tend towards the typical characters of another species, and I cannot but think that the sexual immaturity of all three specimens (considering their large size) is strong evidence of hybridity. As to whether the female 
parent was brill or turbot there is little evidence, but perhaps the preponderance of brill-like characters seems to point to the former species. Within the limits of a single species (e.g. Salmo levenensis) it is the characters (of size and pigmentation) of the female parent that are reproduced in the offspring (Sir J. Gibson Maitland, Bart., in litt.), and it is not unreasonable to suppose that the species of that parent may be predominant in determining the characters of a hybrid. Ova of the brill have been successfully impregnated with the milt of the turbot by Professor M'Intosh, and although the larvæ proved delicate, they do not appear to have been less hardy than pure-bred turbot larvæ which have come under my own observation.

Of the several instances of supposed hybrids collected by Smith (op. cit., pp. 444 and 446) all seem to have been somewhat turbotlike in shape, and the author's conjectures as to the parentage seem to be based chiefly on the number of fin-rays and the relative thickness of the scales. The form which appears to correspond most nearly to those which form the subject of this note is suggested to be the result of the union of the male turbot and female brill, and on the whole I am inclined to think that this interpretation of the parentage is correct. 